\title{
Ectopic ACTH Production in Carcinoma of the Lung
}

\author{
George Gewirtz and Rosalyn S. Yalow \\ From the Solomon A. Berson Research Laboratory, Veterans Administration \\ Hospital, Bronx, New York 10468 and the Department of Medicine, Mt. Sinai \\ School of Medicine, The City University of New York, New York 10029
}

A B S T R A C T Immunoreactive $\mathrm{ACTH}$ was found in almost all tissue extracts of lung carcinoma from patients without clinical evidence of Cushing's syndrome; i.e. 14 of 15 primary tumors, nine of nine metastatic lymph nodes, and four of four metastatic liver nodules contained immunoreactive ACTH. The incidence of ACTH in extracts of other tumor types was much lower. Comparable normal tissues contained no detectable ACTH. Immunoreactive growth hormone, parathyroid hormone, or gastrin was not found in the same carcinoma tissue. The predominant form of $\mathrm{ACTH}$ in the tumor extracts was big ACTH. In pituitary extracts little ACTH predominated.

$53 \%$ of 83 patients with lung carcinoma had afternoon plasma ACTH levels greater than $150 \mathrm{pg} / \mathrm{ml}$; more than $90 \%$ of plasmas containing less than 150 $\mathrm{pg} / \mathrm{ml}$ were obtained from patients who had received radiation therapy or chemotherapy. $31 \%$ of 45 patients with chronic obstructive pulmonary disease (COPD), $28 \%$ of 25 patients with other severe lung disease, and $6 \%$ of 33 controls had elevated values. Big $\mathrm{ACTH}$ predominated in the plasma of patients with lung carcinoma or COPD having elevated ACTH levels. Tissue from the lung of a smoking dog with atypical histologic changes contained immunoreactive ACTH, almost exclusively in the big form, while tissue from another smoking dog that was histologically normal contained no ACTH. Thus ACTH may be present even in precancerous lung lesions. These studies suggest that serial plasma ACTH levels may be of value in screening for, and/or management of, patients with carcinoma of the lung.

\section{INTRODUCTION}

The ectopic production of ACTH associated with a well-defined clinical variant of Cushing's syndrome has been described in patients with tumors of diverse tissue

Reccived for publication 12 September 1973 and in revised form 15 November 1973. origin (See reference 1 for review). However, carcinoma of the lung has been the tumor most commonly associated with ectopic ACTH production (1). Big $\mathrm{ACTH}$, an immunoreactive form of ACTH that is considerably larger than the well characterized 39 amino acid polypeptide (little $\mathrm{ACTH}$ ), has recently been described as the major component of ACTH in the plasma of two patients with ectopic ACTH production and Cushing's syndrome $(2,3)$. Since big ACTH has only minimal in vitro biologic activity $(4,5)$ the possibility of demonstrating tumor production of immunoreactive ACTH, even in the absence of clinical Cushing's syndrome, was suggested (6).

In this report we describe the incidence, concentration and immunologic forms of $\mathrm{ACTH}$ in tumor tissue (primarily carcinoma of the lung) from patients with and without Cushing's syndrome. The concentrations and immunologic forms of $\mathrm{ACTH}$ in the plasma of such patients is compared with those of patients with chronic obstructive pulmonary disease (COPD), other severe lung disease and a control group. Whether plasma ACTH may serve as a useful biologic marker for the presence of carcinoma of the lung is considered.

\section{METHODS}

Tissue extracts from human tumor, pituitary gland, and normal tissue were prepared from freshly frozen tissues obtained at surgery or at autopsy. Generally the time from death to autopsy was not known. To our knowledge careful studies on the rapidity with which pituitary or tumor hormone concentration declines after death have not been performed.

The tissues were sectioned while still frozen, minced, and homogenized for $1 \mathrm{~min}$ with a Teflon pestle at $4^{\circ} \mathrm{C}$ at a concentration of $0.1 \mathrm{~g}$ tissue $/ \mathrm{ml}$ in either $20 \%$ acetone: $1 \%$ acetic acid, $8 \mathrm{M}$ urea, or distilled water. The distilled water extract was then boiled for $3 \mathrm{~min}$ and immediately cooled. After centrifugation of all extracts at $3,000 \mathrm{rpm}$ for $5 \mathrm{~min}$ at $4^{\circ} \mathrm{C}$ the sedimented cell debris was discarded, and portions of the supernatants were subjected to radioimmunoassay.

Extracting vessels were meticulously cleaned between successive extractions by washing successively with solu- 
tions of detergent, acetone-acetic acid, and acetone. Normal tissue was then extracted to verify freedom from contamination. Since nonspecific lowering of the $B / F$ ratio might falsely be attributed to apparent hormone concentration, tissue extracts were subjected to Sephadex gel filtration to assure that the bulk of the apparent hormonal material had filtration characteristics of big or little ACTH.

Plasma samples were generally obtained in the late afternoon to avoid the early morning peak in diurnal levels. Heparinized samples were drawn from in-hospital patients with a tissue diagnosis of carcinoma of the lung or with clinical diagnoses of chronic obstructive pulmonary disease or pulmonary tuberculosis. Most of the samples were obtained from patients at the East Orange or Bronx Veterans Administration Hospitals, although occasional samples were provided from other sources. Plasma samples from normal laboratory personnel and out-patients of our thyroid clinic with no known pertinent disease served as controls.

The immunoreactive ACTH content of tumor extracts and plasma samples was determined by radioimmunoassay with a sensitivity of $1-2 \mathrm{pg} / \mathrm{ml}$ incubation mixture according to methods previously described $(3,7)$. It was considered desirable to verify the nature of the immunoreactive material by Sephadex gel filtration. To perform this study the minimal concentration in the tissue which could be detected was 2-4 ng immunoreactive ACTH per gram of tissue. The acetone-acetic acid extracts were also assayed for immunoreactive growth hormone (8) and parathyroid hormone (9), and the boiled water extracts were assayed for immunoreactive gastrin (10) according to methods established in this laboratory.

To determine the relative fraction of big and little ACTH in tissue extracts and plasma samples, portions were subjected to gel filtration at $4^{\circ} \mathrm{C}$ on Sephadex G-50 fine columns, $1 \mathrm{~cm} \times 50 \mathrm{~cm}$. Volumes up to $3 \mathrm{ml}$ were applied to the columns. The extracts were fortified with trace amounts of [ $\left.{ }^{131} \mathrm{I}\right]$ albumin, [ $\left.{ }^{125} \mathrm{I}\right] \mathrm{ACTH}$, and $\left[{ }^{131} \mathrm{I}\right] \mathrm{Na}$, which served as markers, before being placed on the columns. The columns were eluted with $0.1 \mathrm{M} \mathrm{NaCl}$ containing $10 \%$ hormone-free plasma and $0.5 \%$ 2-mercaptoethanol. Successive $1 \mathrm{ml}$ fractions were collected and counted for radioactivity, and appropriate portions up to 1 $\mathrm{ml}$ were subjected to radioimmunoassay $(3,7)$. The observed trailing of immunoreactive ACTH beyond the zone of elution of authentic big or little ACTH may arise

\section{TABLE I}

Incidence of Immunoreactive ACTH in Tissue Extracts from Patients with Carcinoma of the Lung without Clinical Cushing's Syndrome

\begin{tabular}{lc}
\hline \multicolumn{1}{c}{ Tissue } & Incidence \\
\hline Carcinoma of lung & \\
Primary tumor & $14 / 15$ \\
Lymph node metastasis & $9 / 9$ \\
Liver metastasis & $4 / 4$ \\
Lung tissue & \\
Distant from tumor & $0 / 8$ \\
Adjacent to tumor & $2 / 8$ \\
Normal liver & $0 / 2$ \\
\hline
\end{tabular}

TABLE II

Incidence of Immunoreactive ACTH in Tumor and Normal Tissue Extracts from Patients without Clinical Cushing's Syndrome

\begin{tabular}{ll}
\hline \multicolumn{1}{c}{ Tissue } & Incidence \\
\hline Lung & \\
Bronchial adenoma & $1 / 1$ \\
Normal lung & $0 / 10$ \\
Pancreas & \\
Insulinoma & $1 / 7$ \\
Nonbeta cell tumor (Z-E syndrome) & $1 / 2$ \\
Normal pancreas & $0 / 2$ \\
Esophagus & \\
Carcinoma & $0 / 1$ \\
Normal esophagus & $0 / 1$ \\
Colon & \\
Carcinoma & $0 / 1$ \\
Normal colon & $0 / 1$ \\
Kidney & \\
Carcinoma & \\
Normal kidney & $0 / 2$ \\
Thymus & $0 / 2$ \\
Thymoma & \\
Normal thymus & $0 / 2$ \\
Liver & $0 / 2$ \\
Hepatoma & \\
Normal liver & $0 / 1$ \\
\hline & $0 / 2$ \\
\hline
\end{tabular}

in part from proteolytic degradation of hormone in the extracts, chemical artifacts introduced in the extraction procedure, etc. It is less commonly observed with plasma than with tissue extracts.

Several patients with elevated plasma levels of big ACTH were given an intravenous infusion of $300 \mathrm{mg}$ of hydrocortisone over a $3 \mathrm{~h}$ period. Plasma samples were drawn at frequent intervals during the infusion for ACTH determination.

In a blind study, tissue specimens from the lungs of two dogs that had been smoking for 105 days on a smoking machine ${ }^{1}$ were extracted with boiled water and subjected to immunoassay. The extract that contained ACTH was fractionated on Sephadex G-50 as described above.

Plasma cortisol levels were determined ${ }^{2}$ by competitive binding assay (11) on samples containing greater than $150 \mathrm{pg} / \mathrm{ml}$ immunoreactive ACTH.

\section{RESULTS}

Table I shows the incidence of immunoreactive ACTH in tissue extracts from patients with carcinoma of the

\footnotetext{
1 These specimens were provided to us by Dr. Oscar Auerbach, Senior Medical Investigator, Veterans Administration Hospital, East Orange, N. J.

These assays were performed in the laboratory of Dr. Dorothy Krieger by Mr. Anthony Liotta.
} 

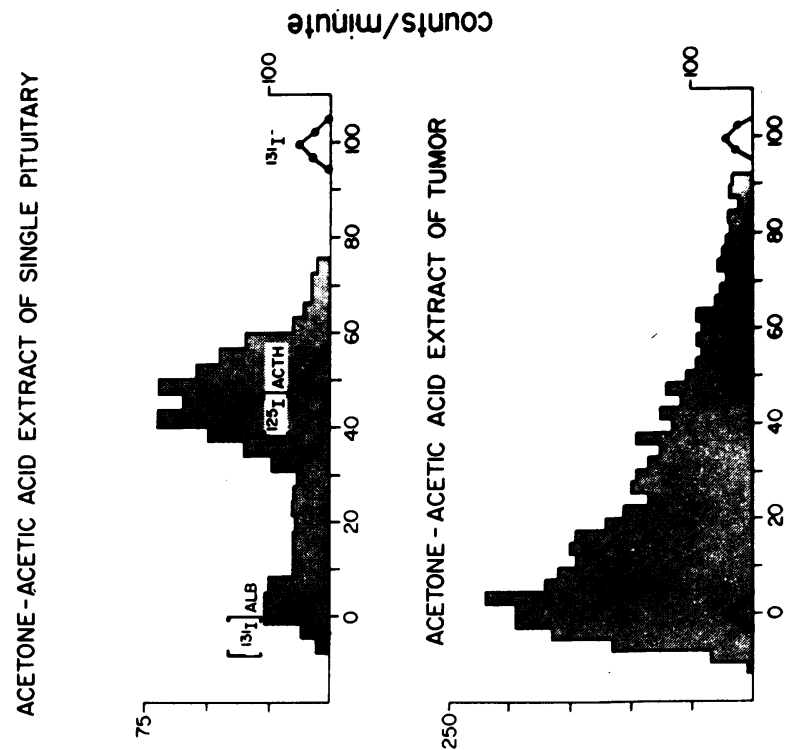

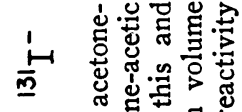

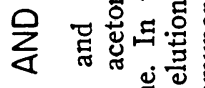

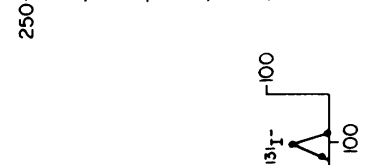

๖

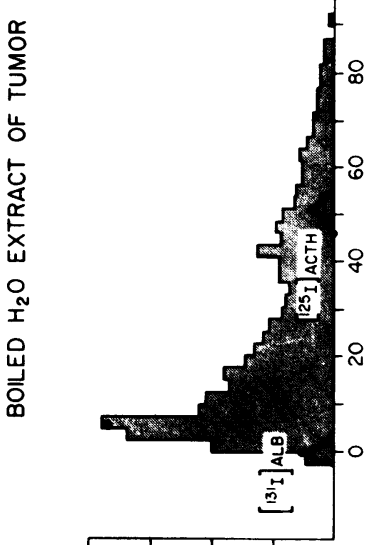

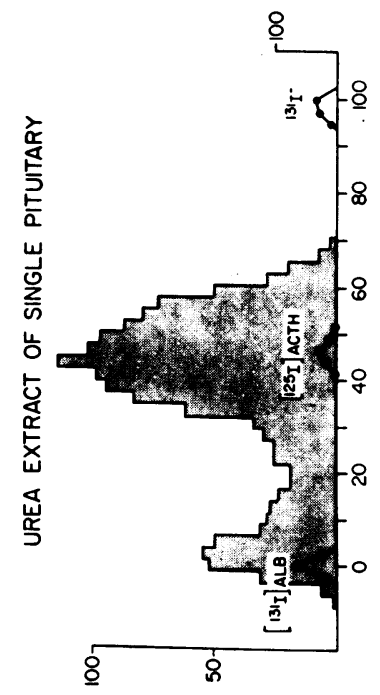

$\mu / 6 u$

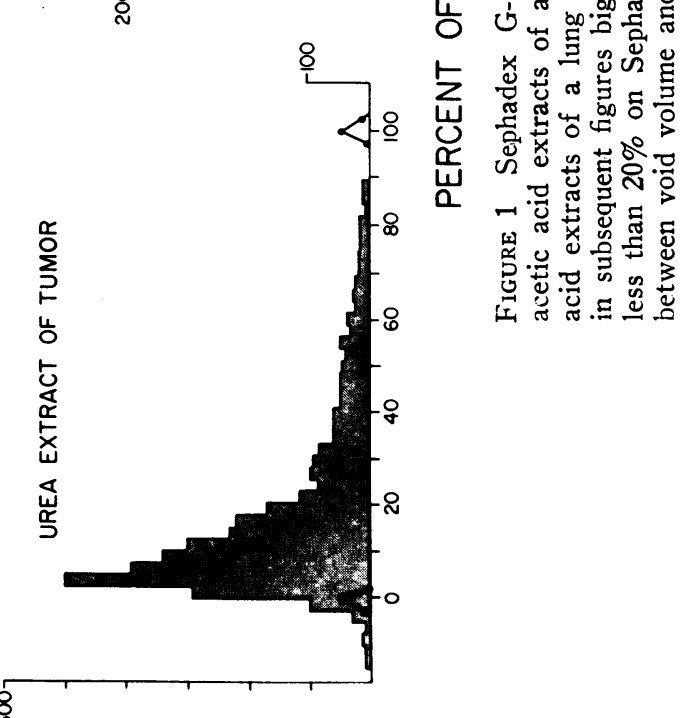

iw/6d

$S \exists \perp \forall \cap 7 \exists \mathrm{NI} N O I \perp \forall Y \perp N \exists J N O O \quad H \perp J \forall$ 


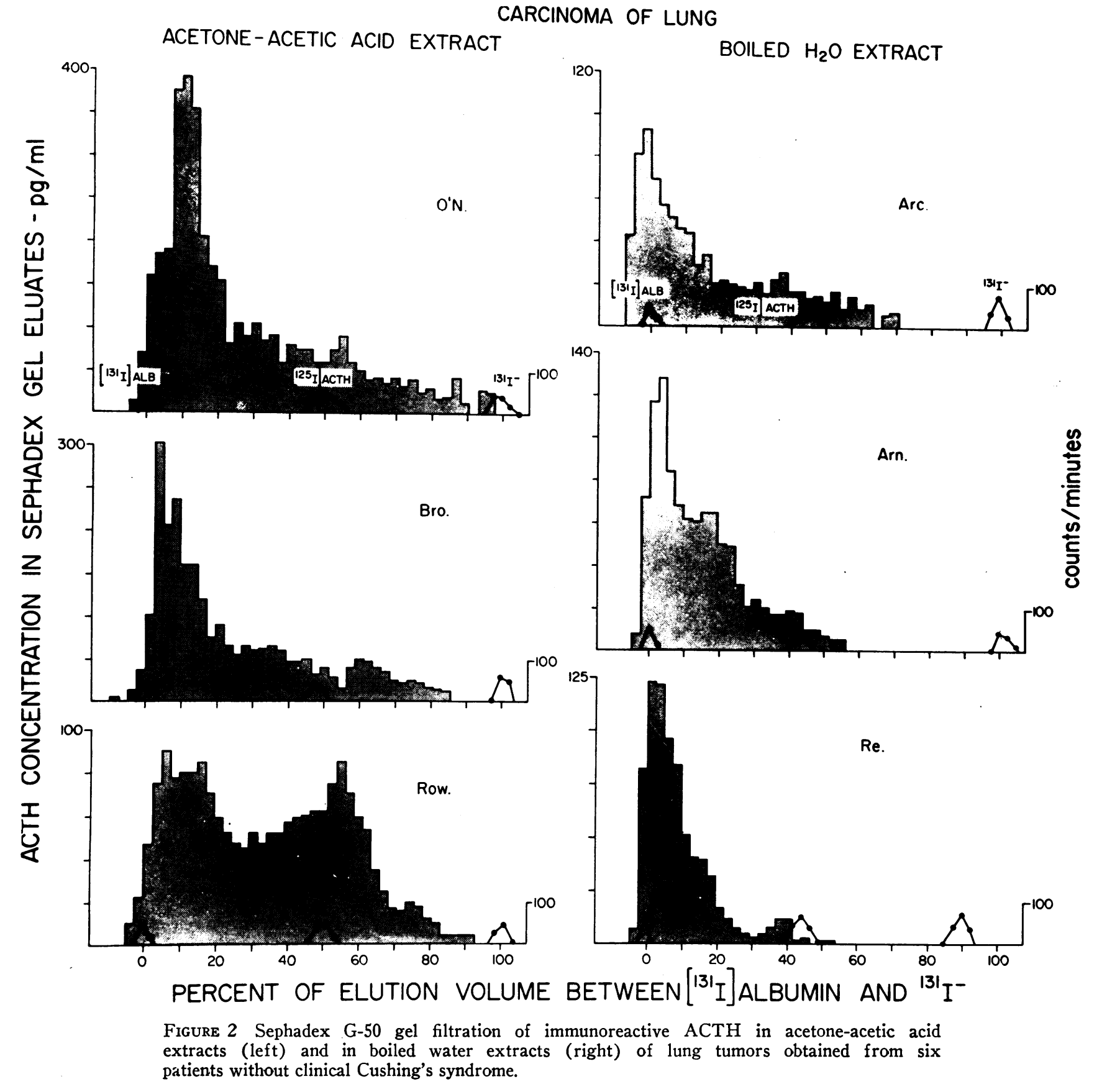

lung without clinical evidence of Cushing's syndrome. ACTH was present in 14 out of 15 extracts of primary tumor. The one carcinoma of the lung that did not contain ACTH had been defrosted for a period of several hours prior to extraction, which may have resulted in degradation of the hormone. Nine out of nine lymph node metastases and four out of four liver metastases also contained immunoreactive ACTH. All the metastatic tissue and all but three of the primary tumors were ob-

tained at autopsy. The hormonal content of surgical specimens compared with that of post-mortem specimens has not been carefully studied. ACTH was not found in eight extracts of lung tissue distant from the tumor site obtained from the same patients or in normal liver tissue. Two of eight extracts of lung tissue adjacent to the tumor contained ACTH; this may reflect the presence of undetected tumor infiltration. No immunoreactive parathyroid hormone or growth hormone was present in 


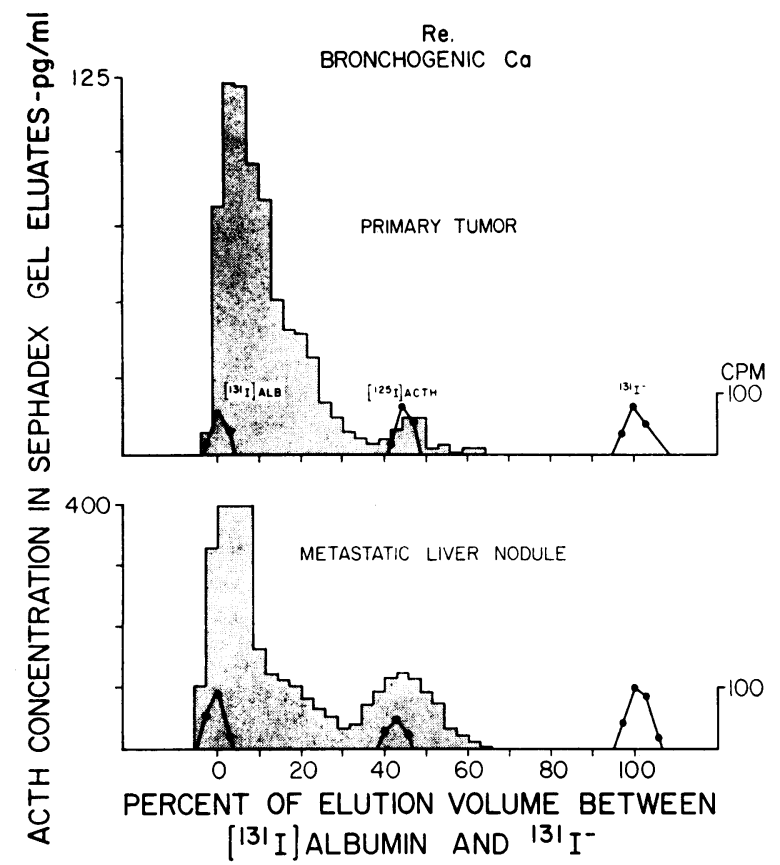

FIgURE 3 Sephadex G-50 gel filtration of immunoreactive ACTH in a primary tumor (top) and a metastatic liver nodule (bottom) of a patient with a bronchogenic carcinoma without clinical Cushing's syndrome.

seven acetone-acetic acid extracts of lung carcinoma, and no immunoreactive gastrin was present in six boiledwater extracts of lung carcinoma. The primary lung tumors and metastases included squamous cell carcinoma, adenocarcinoma, and oat cell carcinoma in fairly equal distribution.

The remarkably high incidence of immunoreactive ACTH in carcinoma of the lung contrasts sharply with the incidence in other tumor types as is shown in $\mathrm{Ta}$ ble II. The single bronchial adenoma studied, one of seven insulinomas, and one of two Zollinger-Ellison tumors contained ACTH. ACTH was not present in other tumor or normal tissue extracts.

The concentration of immunoreactive ACTH in car-

TABLE III

Immunoreactive ACTH in Tissue Extracts

\begin{tabular}{lcc}
\hline \multicolumn{1}{c}{ Tissue } & $\begin{array}{c}\text { ACTH } \\
\text { concentration* }\end{array}$ & $\begin{array}{c}\text { Fraction } \\
\text { big ACTH }\end{array}$ \\
\hline Pituitary & $0.035-6.5 \mathrm{mg} / \mathrm{g}$ & $0.15-0.25$ \\
Tumor with ectopic ACTH syndrome & $1.75-2.5 \mu \mathrm{g} / \mathrm{g}$ & $0.35-0.70$ \\
Carcinoma of lung & & \\
$\quad$ Primary & $5.0-55.0 \mathrm{ng} / \mathrm{g}$ & $0.60-1.00$ \\
Lymph node metastasis & $4.5-8.0 \mathrm{ng} / \mathrm{g}$ & $0.75-1.00$ \\
Liver metastasis & $4.0-55.6 \mathrm{ng} / \mathrm{g}$ & $0.80-1.00$ \\
\hline
\end{tabular}

* Concentration is expressed as ACTH mass content immunochemically equivalent to the 1-39 peptide per gram of wet weight of tissue. cinoma of the lung ranged from $5.0 \mathrm{ng} / \mathrm{g}$ wet tissue to $55.0 \mathrm{ng} / \mathrm{g}$ (Table III). Similar concentrations were found in lymph node and liver metastases. From Table III it can be seen that these concentrations are generally much less than we have found in tumors from patients with ectopic Cushing's syndrome and generally less than $0.1 \%$ of the concentration observed in the pituitary using the same extraction procedures.

Fig. 1 compares the Sephadex gel filtration patterns of different extracts of a normal pituitary gland and of a lung tumor from a patient without ectopic Cushing's syndrome. In these and subsequent Sephadex gel filtration studies the recoveries after fractionation ranged from 65 to $110 \%$ of the total immunoreactive ACTH levels. Gel filtration patterns of acetone-acetic acid or $8 \mathrm{M}$ urea extracts of the pituitary were similar and demonstrated a minor component with an elution volume about the same as labeled albumin and a major component with the same elution volume as labeled 1-39 peptide. These two components are big ACTH and little $\mathrm{ACTH}$, respectively. In marked contrast, the elution patterns of the lung tumor irrespective of extraction procedure showed big ACTH to predominate. Some immunoreactivity was found between the two major peaks in all tissue extracts. Extraction of the same lung tumor with acetone-acetic acid, boiled water, or $8 \mathrm{M}$

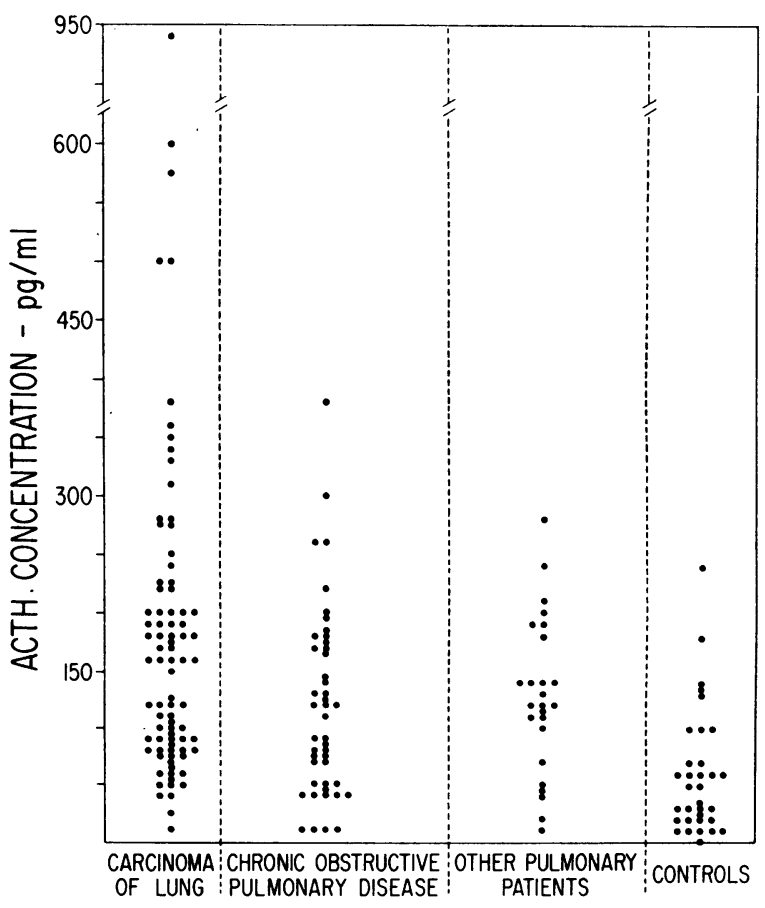

Figure 4 Scattergram of immunoreactive ACTH concentrations in afternoon plasma specimens from patients with carcinoma of the lung, chronic obstructive pulmonary disease, and other pulmonary patients and controls. 


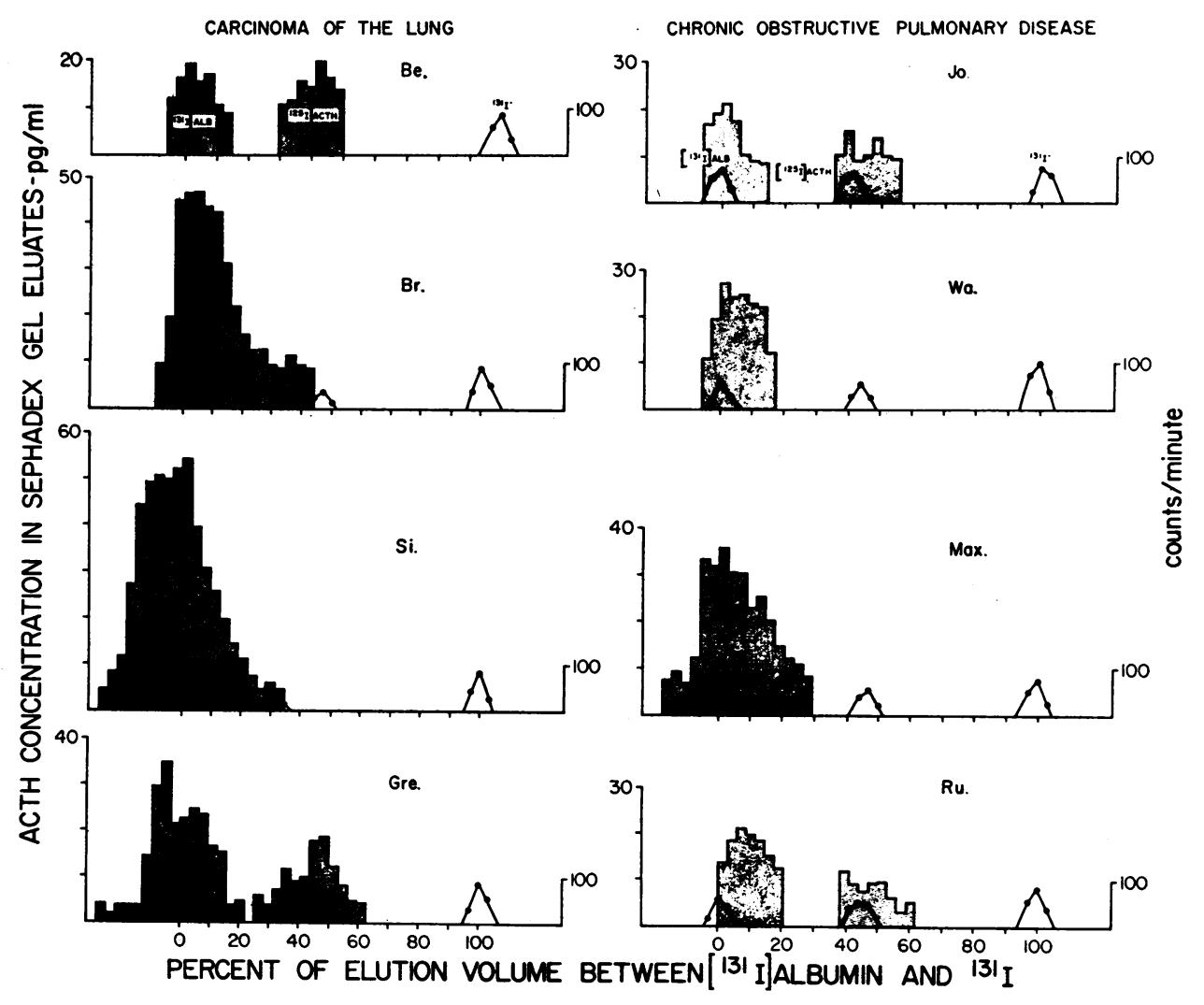

FIGURE 5 Distribution of immunoreactive $\mathrm{ACTH}$ in the plasma of patients with carcinoma of the lung (left) and with chronic obstructive pulmonary disease (right).

urea generally resulted in no significant differences in the total immunoreactive ACTH recovered or in the percentage of big ACTH present (Fig. 1).

The distribution of hormonal forms in six other lung carcinoma tissues extracted with two of the solvents is shown in Fig. 2. In five out of six extracts the ACTH was almost exclusively big; in the sixth, patient Row., the two immunoreactive components were present in fairly equal amounts.

In Fig. 3 are shown the gel filtration patterns of immunoreactive ACTH from the primary lung tumor and from a metastatic liver nodule of a patient without ectopic Cushing's syndrome. The ACTH concentration of the liver nodule was three times that of the primary lung tumor. In both tissues the content of big ACTH greatly exceeded that of little ACTH.

The relative concentration of the two immunoreactive components in tissue extracts is summarized in Table III. Big ACTH generally comprised more than $60 \%$ of the immunoreactive ACTH in the primary tumor, more than $75 \%$ in lymph node metastases and more than $80 \%$ in liver metastases in patients with carcinoma of the lung without Cushing's syndrome. In three patients with ectopic Cushing's syndrome the fraction of big
$\mathrm{ACTH}$ in the tumor extracts ranged from 35 to $70 \%$. However, pituitaries obtained at autopsy from patients not known to have pituitary disease had only $15-25 \%$ big ACTH.

In view of the ubiquitous presence of immunoreactive ACTH in primary and metastatic carcinoma of the lung, the concentrations of immunoreactive ACTH in the plasma of such patients was determined (Fig. 4). 53\% of 83 patients with carcinoma of the lung had ACTH concentrations in afternoon specimens greater than 150 $\mathrm{pg} / \mathrm{ml}$. Over $90 \%$ of the plasma specimens with values less than $150 \mathrm{pg} / \mathrm{ml}$ were obtained from patients with a history of radiation therapy or chemotherapy. Two of the untreated patients in this group had a tissue diagnosis of well-differentiated epidermoid carcinoma and are alive and in good clinical condition $2 \mathrm{yr}$ after the initial diagnosis. Only $31 \%$ of 45 patients with chronic obstructive pulmonary disease, $28 \%$ of 25 patients with other severe lung disease, and $6 \%$ of 33 controls had these elevated values.

Fractionation of plasma containing elevated ACTH concentrations (Fig. 5) revealed no difference in patterns observed in patients with lung carcinoma (40-90\% big $\mathrm{ACTH}$ ) and chronic obstructive pulmonary disease 


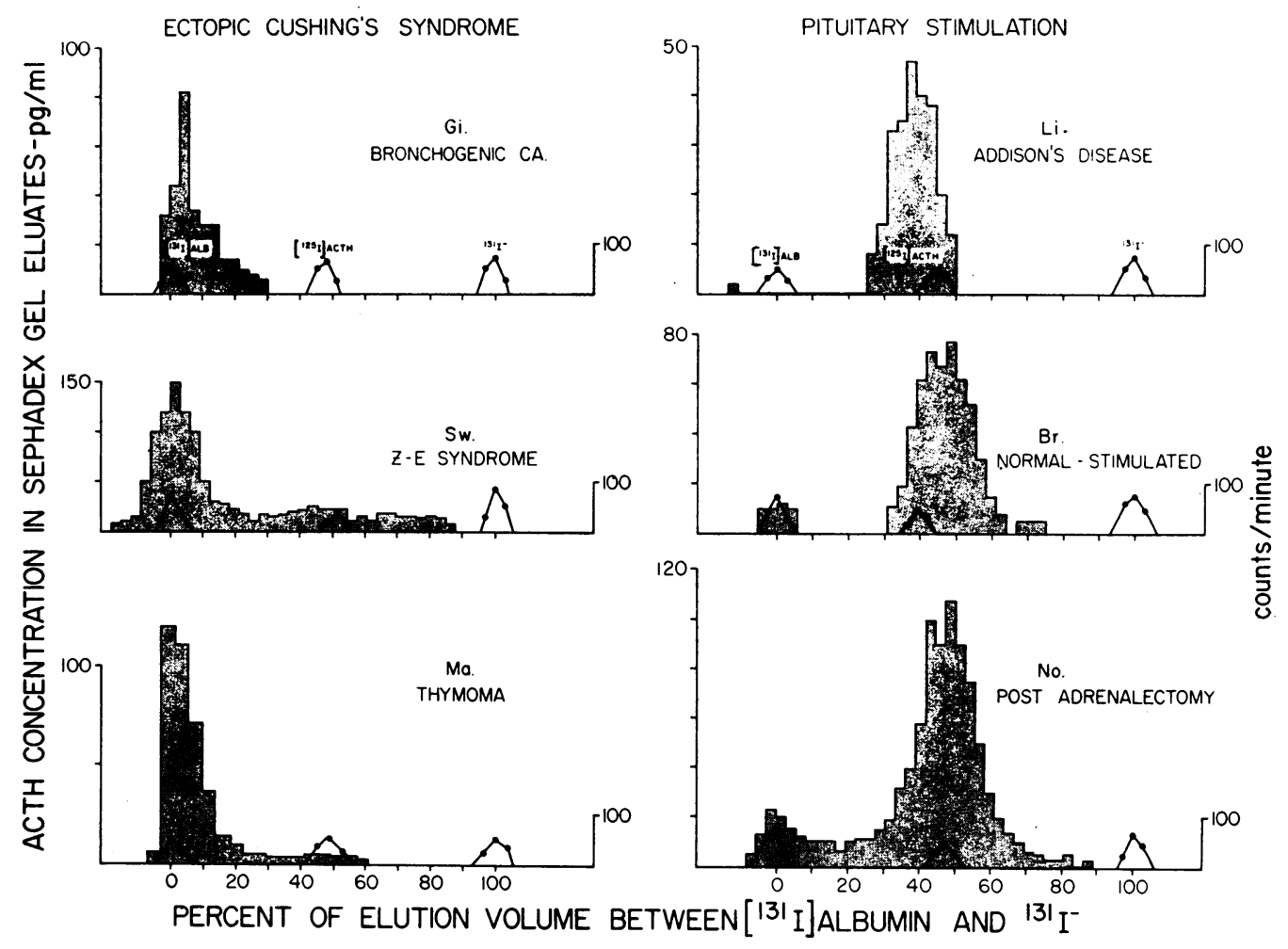

FJGURE 6 Distribution of immunoreactive ACTH in the plasma of patients with ectopic Cushing's syndrome (left) and in the plasma of patients following pituitary stimulation (right).

(45-90\%). These patterns contrast sharply with those observed when plasma ACTH is elevated in response to pituitary stimulation (Fig. 6). In Addison's disease,

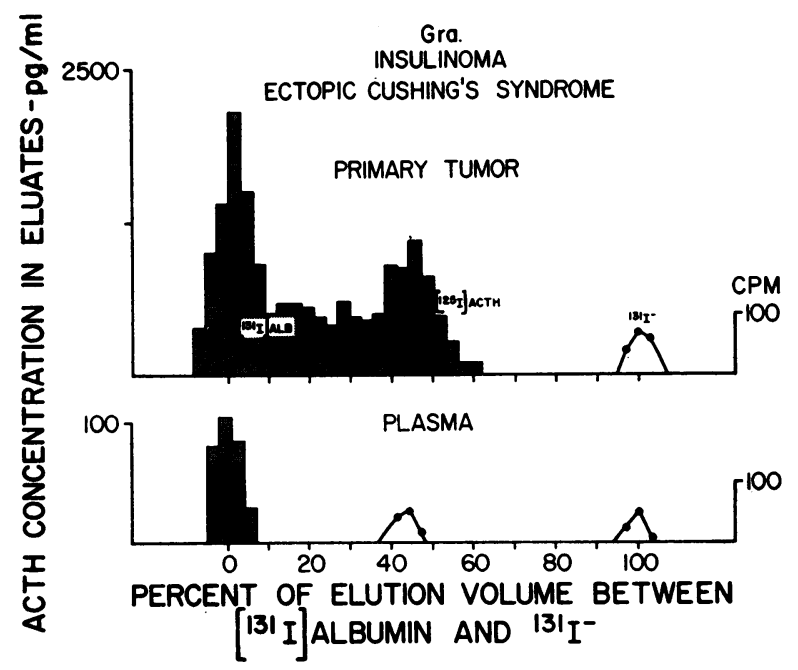

Figure 7 Sephadex G-50 gel filtration of immunoreactive ACTH in the primary tumor (top) and in the plasma (bottom) of a patient with an insulinoma and clinical Cushing's syndrome. in metyrapone stimulation of a normal subject and in a patient after adrenalectomy little ACTH comprised more than $90 \%$ of the immunoreactive ACTH. In six patients with ectopic Cushing's syndrome, three of whom are shown in Fig. 6, more than $90 \%$ of the plasma ACTH was in the big form.

Plasma ACTH does not necessarily reflect tumor $\mathrm{ACTH}$. In a patient with an insulinoma and ectopic Cushing's syndrome only big ACTH was found in the

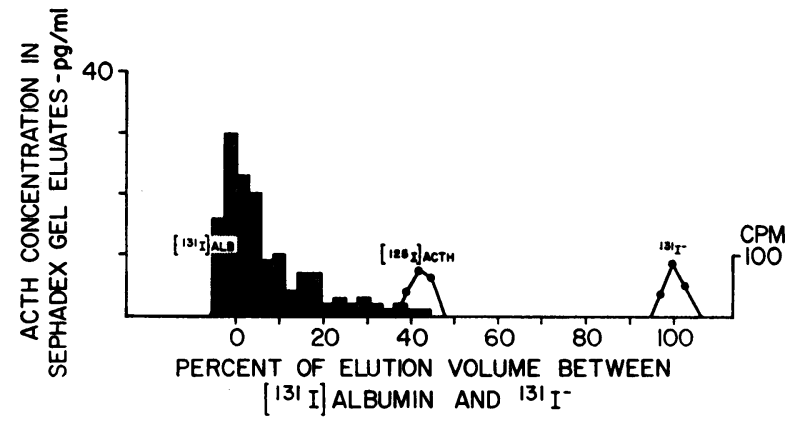

FIGURE 8 Distribution of immunoreactive ACTH in a boiled water extract of lung tissue of a smoking dog with a pathologic diagnosis of atypical histologic changes in the lung parenchyma. 
plasma, and yet the tumor extract had a significant fraction as little ACTH (Fig. 7).

$300 \mathrm{mg}$ of hydrocortisone infused over a $3 \mathrm{~h}$ period failed to suppress elevated plasma ACTH concentrations in patients, with or without Cushing's syndrome, whose plasma samples contained more than $90 \%$ big ACTH.

Whether or not immunoreactive ACTH might be found in lung tissue of smoking dogs, as well as in human carcinoma of the lung, was considered a question of some interest. Therefore, lung tissue was obtained on a blind basis from Dr. Oscar Auerbach from two dogs who had been smoking for 105 days. Tissue from one dog had no significant histologic changes in the lung parenchyma, and an extract of this tissue contained no immunoreactive ACTH. Lung tissue from the second dog showed atypical histologic changes, including basal cell hyperplasia with moderate atypism and atypical proliferation of alveolar living cells. A boiled water extract contained $5 \mathrm{ng}$ of ACTH per gram of wet tissue, which is comparable to that found in the lowest of the human lung carcinoma tissues; $90 \%$ of the immunoreactivity was in the big form (Fig. 8).

Plasma cortisol concentrations were determined for 45 lung carcinoma patients with elevated plasma ACTH. Of these, 39 had plasma cortisol levels less than $20 \mu \mathrm{g}$ / $100 \mathrm{ml}$, five had levels between 20 and $30 \mu \mathrm{g} / 100 \mathrm{ml}$, and one had a plasma level of $33 \mu \mathrm{g} / 100 \mathrm{ml}$.

\section{DISCUSSION}

The ubiquitous presence of immunoreactive ACTH in both the primary and metastatic tumors of patients with carcinoma of the lung without clinical evidence of ectopic Cushing's syndrome is quite remarkable. There was a much lower incidence of ACTH in other tumors and ACTH was not detectable in comparable normal tissues. Some reports had suggested that ectopic ACTH production by lung carcinomas was more common than generally accepted. Hauger-Klevene (12) found either elevated plasma ACTH, lack of diurnal rhythm, or failure to suppress plasma $\mathrm{ACTH}$ by dexamethasone in 8 of 26 patients with lung carcinoma. Only one of the eight had plasma corticoids at 4 p.m. in excess of 30 $\mu \mathrm{g} / 100 \mathrm{ml}$, and six of the eight had values of $20 \mu \mathrm{g} / 100$ $\mathrm{ml}$ or less. Knight and Besser (13) noted the presence of immunoreactive ACTH in tumors of various tissues from patients without clinical Cushing's syndrome as well as from patients with the syndrome. However, in their study (13) the ACTH content of normal tissue extracts was not reported, and, in the absence of appropriate controls, one must consider whether the ACTH detected could have been due to accidental contamination or other nonspecific effects. In their study there was not clear distinction between the tumor content of
ACTH in most patients with ectopic Cushing's syndrome due to oat cell carcinoma of the bronchus and tumors from patients without the syndrome.

The presence of immunoreactive $\mathrm{ACTH}$ and the absence of immunoreactive growth hormone, parathyroid hormone, and gastrin in the same tumors poses an interesting question. What is unique in the nature of the ACTH synthetic system that results in the preferential ectopic production of this hormone in carcinoma of the lung? For instance, if the mechanism of ACTH production in these tumors relates to derepression of genes, why are the genes controlling the synthesis of ACTH affected and not those of other hormones? Beck and Burger (14) have reported that 7 of 18 carcinomas of the lung contained immunoreactive growth hormone and the concentrations they found were well within the limits of our assay. Nonetheless growth hormone was not detectable in any of the tumors in our series.

The finding of a higher fraction of the total immunoreactive $\mathrm{ACTH}$ in the big form in lung tumors as compared with a lower fraction in this form in the pituitary gland is not unexpected. It had earlier been shown (15) that in an islet-cell tumor the fraction of immunochemical insulin in the precursor form, proinsulin, is greater than that in normal pancreatic tissue of the same patient. The high fractional content of big ACTH is consistent with the hypothesis of a defect in the conversion of big to little ACTH. This defect may arise from $(a)$ a qualitative or quantitative deficiency in an enzyme that facilitates the conversion of big ACTH to little ACTH, (b) a defect in the "packaging" of the enzyme together with the big ACTH which results in inhibition of enzymatic conversion, or (c) a factor in tumor tissue which acts as an inhibitor of enzymatic conversion. It is unlikely that preferential release of little ACTH is the mechanism responsible for the relative elevation of big $\mathrm{ACTH}$ in tumor tissue since big ACTH is also the predominant component in the circulation.

Orth, Nicholson, Mitchell, Island, and Liddle have reported a high incidence of $\mathrm{N}$-terminal and $\mathrm{C}$-terminal $\mathrm{ACTH}$ fragments in tumors associated with ectopic Cushing's syndrome (16). The antiserum used in our studies, as previously characterized (17), is highly sensitive to the intact 1-39 ACTH, but is more than 20fold less sensitive to the biologically active 1-24 N-terminal fragment and even less sensitive to the biologically inactive intermediate and C-terminal ACTH fragments. It is therefore not surprising that immunoactive ACTH having an elution volume larger than that of the 1-39 peptide was not detected in our study. Furthermore Orth et al. (16) in their tumor extracts did not find an immunoactive ACTH corresponding to the big ACTH reported here. However their tumors were extracted and partially purified by cation-exchange chromatog- 
raphy prior to fractionation and immunoassay. Dr. Teh Lee (personal communication) has recently found that, unlike little ACTH, big ACTH is not well-absorbed by oxycellulose, and consideration should be given to the possibility that because of different chemical properties big ACTH may have been preferentially excluded by partial purification of the tissue and plasma extracts prepared by Orth et al. (16). As previously reported (3) the antiserum we use for assay appears to react identically with both big and little ACTH. Whether the failure of Orth et al. (16) to detect big ACTH is due to low sensitivity of the antisera they employed for the detection of the big hormonal form has not been determined.

The presence of immunoreactive $\mathrm{ACTH}$, primarily in the big form, in almost all tissue obtained from either primary or metastatic carcinoma of the lung suggested the possibility that elevated immunoreactive ACTH levels in plasma could serve as a biologic marker for the detection of this disease. To evaluate this possibility plasma sampling was performed in the late afternoon to avoid the early morning spurt in ACTH concentrations associated with the normal diurnal rhythm. We have earlier reported (7) that occasional high afternoon concentrations of ACTH are found even in normal subjects; this is due to sporadic fluctuations in ACTH levels. Therefore to eliminate falsely positive elevations of plasma ACTH in normal subjects multiple sampling and/or dexamethasone suppression should have been employed. In spite of the failure to observe this precaution, over $94 \%$ of normal control subjects in this study had afternoon ACTH levels below $150 \mathrm{pg} / \mathrm{ml}$. In less than half the patients with proven carcinoma of the lung was plasma immunoreactive ACTH below 150 $\mathrm{pg} / \mathrm{ml}$. Of the patients with these low values more than $90 \%$ had received extensive radiation and/or chemotherapy. Several of the patients with low plasma ACTH levels who have come to autopsy have had tumor necrosis of varying degree. The lowest plasma ACTH concentrations among the untreated patients were found in two subjects with well-differentiated epidermoid carcinoma who are alive and in good clinical condition $2 \mathrm{yr}$ after diagnosis. In one of these two the tumor appeared so dormant that it was recently rebiopsied to confirm the original diagnosis. The highest ACTH concentrations $(>300 \mathrm{pg} / \mathrm{ml}$ ) were found in the lung carcinoma patients with no record of previous antitumor therapy. It is especially pertinent to note that one patient initially included in the COPD group and who had had the highest plasma ACTH concentration in this group was subsequently found to have a rapidly g:owing carcinoma of the lung. Although these data on the relationship of plasma ACTH to tumor activity are preliminary, they suggest that one should investigate the possibility that elevation of plasma immunoreactive ACTH may be associated with the virulence of the bronchogenic tumor.

The absence of clinical Cushing's syndrome in the patients with elevated plasma immunoreactive ACTH is consistent with the absence of marked elevation of plasma cortisol in these patients. This is not unexpected in view of the observation that the predominant form in the plasma of patients with ectopic hormone production is big ACTH. Our studies have shown that the biologic activity of big ACTH is less than $4 \%$ of its immunologic potency $(4,5)$. Whether biologic potency at a low level is characteristic of big ACTH or whether big $\mathrm{ACTH}$ is devoid of biologic activity and the $4 \%$ represents undetected in vitro conversion to little ACTH was not resolved. Nonetheless, big ACTH concentrations would have to be increased at least 25 -fold in order to have a biologic effect equivalent to that of little $\mathrm{ACTH}$, the form usually found associated with pituitary stimulation. Thus clinical Cushing's syndrome could be expected only if the big ACTH concentrations were markedly elevated and in excess of $1 \mathrm{ng} / \mathrm{ml}$.

Although the highest concentrations of $\mathrm{ACTH}$ are not found in patients with COPD, $31 \%$ of them did have plasma ACTH in excess of $150 \mathrm{pg} / \mathrm{ml}$. Since heavy smokers are found in this group, the possibility of an undetected carcinoma must always be considered when such a patient presents with markedly elevated plasma ACTH. This was the case in the patient described earlier. Moreover the finding of big ACTH in the smoking dog with atypical histologic changes but not carcinoma suggests that ectopic hormone production may occur even before a definitive histologic diagnosis of carcinoma can be made. Furthermore, although we have not as yet had the opportunity of assaying autopsy material from patients with COPD, several of the COPD patients reported in this series were found at autopsy to have squamous metaplasia and focal mucosal changes with atypia of marked degree (Dr. L. Fred Ayvazian, personal communication). Certainly more data are required to evaluate the incidence of detectable ACTH in the absence of overt cancerous lesions of man and dog. Nonetheless the findings so far are suggestive that the difference between the early atypical histologic changes and cancerous lesions with respect to ACTH content may be quantitative rather than qualitative.

In patients with severe lung disease other than carcinoma of the lung or COPD, $28 \%$ had ACTH levels between 150 and $300 \mathrm{pg} / \mathrm{ml}$. The distribution between little and big ACTH was not determined in these samples nor were the control procedures of dexamethasone suppression or multiple sampling used to evaluate whether the elevated levels were simply secondary to the stress of severe disease. It has been our experience that an infusion of $300 \mathrm{mg}$ of hydrocortisone over a $3 \mathrm{~h}$ 
period rapidly returns metyrapone-stimulated ACTH levels to normal (7), while, as reported here, a similar infusion fails to suppress the big component of immunoreactive $\mathrm{ACTH}$. Certainly steroid suppression studies should be incorporated in future protocols concerned with the possible value of elevations of immunoreactive $\mathrm{ACTH}$ as a biologic marker. It would appear as if little ACTH, which is the predominant hormonal component after pituitary stimulation, is more readily suppressible by steroids than-is big ACTH. Whether big ACTH of pituitary origin is responsive to ACTH suppression was not directly elevated in these studies, but the long turnover time for this hormonal form (unpublished observations) would preclude a rapid drop in its circulating level during acute steroid administration under any circumstances.

The cogent features of this study relate to the ubiquitous presence of immunoreactive ACTH, in the absence of detectable amounts of several other hormones, in carcinoma of the lung, irrespective of tumor type. The tantalizing observation of the presence of ACTH in the lung tissue of a smoking dog with atypical histologic changes requires further confirmation but is suggestive that the ACTH synthesis may develop even in advance of the malignant phase of the disease. The question of the usefulness of plasma ACTH concentrations as a screening procedure for the early detection of carcinoma of the lung cannot be answered unequivocally. The number of false positive determinations can be expected to be reduced by multiple sampling of afternoon samples and by the use of dexamethasone to suppress pituitary ACTH secretion. When carcinoma is detected early, the patient is likely not to be severely ill, and thus the question as to whether severe stress-related secretion of pituitary ACTH is manifest even in the presence of dexamethasone is irrelevant. The preliminary results on plasma concentrations in patients with carcinoma of the lung presented in this report suggest that there may be some correlation between elevation of plasma ACTH and virulence of the tumor. These studies would suggest that, at present, mass screening of a large population for occult carcinoma of the lung might be premature but that serial plasma immunoreactive ACTH determinations might serve as an objective test for rate of tumor progression or for efficacy of therapeutic regimens.

\section{ACKNOWLEDGMENTS}

The authors are greatly indebted to Doctors L. Fred Ayvazian and Clarito L. Garces of the East Orange Veterans Administration Hospital who provided many of the plasma and tissue specimens and clinical data on the patients reported in this study. We are indebted also to Dr. Oscar Auerbach who provided the tissue samples and the histologic diagnosis on the smoking dogs.
The ACTH preparations used for labeling and standards were provided by the National Pituitary Agency.

This is project no 9678-01 of the Veterans Administration.

\section{REFER ENCES}

1. Liddle, G. W., W. E. Nicholson, D. P. Island, D. N. Orth, K. Abe, and S. C. Lowder. 1969. Clinical and laboratory studies of ectopic humoral syndromes. Rec. Prog. Horm. Res. 25 : 283.

2. Yalow, R. S., and S. A. Berson. 1971. Size heterogeneity of immunoreactive human ACTH in plasma and in extracts of pituitary glands and ACTH-producing thymoma. Biochem. Biophys. Res. Commun. 44: 439.

3. Yalow, R. S., and S. A. Berson. 1973. Characteristics of "big ACTH" in human plasma and pituitary extracts. J. Clin. Endocrinol. Metab. 36: 415.

4. Schneider, B., G. Gewirtz, D. T. Krieger, and R. S. Yalow. 1973. Big ACTH: conversion to biologically active ACTH by trypsin. Endocrinology. 92 (Suppl.) : A-52.

5. Gewirtz, G., B. Schneider, D. T. Krieger, and R. S. Yalow. 1974. Big ACTH: conversion to biologically active ACTH by trypsin. J. Clin. Endocrinol. Metab. 38: 59 .

6. Gewirtz, G., and R. S. Yalow. 1973. Ectopic ACTH production: big and little forms. Endocrinology. 92 (Suppl.) : A-53.

7. Berson, S. A., and R. S. Yalow. 1968. Radioimmuno. assay of ACTH in plasma. J. Clin. Invest. 47: 2725.

8. Berson, S. A., and R. S. Yalow. 1973. Growth hormone radioimmunoassay. In Methods in Investigative and Diagnostic Endocrinology, Part II. Pituitary Hormones and Hypothalamic Releasing Factors. S. A. Berson and R. S. Yalow, editors. American Elsevier Publishing Co., Inc., New York. 302.

9. Yalow, R. S., and S. A. Berson. 1973. Parathyroid hormone radioimmunoassay. In Methods in Investigative and Diagnostic Endocrinology, Part III. Non-Pituitary Hormones. S. A. Berson and R. S. Yalow, editors. American Elsevier Publishing Co., New York. 969.

10. Yalow, R. S., and S. A. Berson. 1973. Radioimmunoassay of gastrin. In Methods in Investigative and $\mathrm{Di}$ agnostic Endocrinology, Part III. Non-Pituitary Hormones. S. A. Berson and R. S. Yalow, editors. American Elsevier Publishing Co., Inc., New York. 1043.

11. Murphy, B. E. P. 1967. Some studies of the proteinbinding of steroids and their application to the routine micro and ultramicro measurement of various steroids in body fluids by competitive protein-binding radioassay. J. Clin. Endocrinol. Metab. 27: 973.

12. Hauger-Klevene, J. H. 1968. Asymptomatic production of ACTH. Radioimmunoassay in squamous cell, oat cell and adenocarcinoma of the lung. Cancer. 22: 1262.

13. Knight, R. A., J. G. Ratcliffe, and G. M. Besser. 1971. Tumour ACTH concentrations in ectopic ACTH syndrome and in control tissue. Proc. Roy. Soc. Med. 64: 1266.

14. Beck, C., and H. G. Burger. 1972. Evidence for the presence of immunoreactive growth hormone in cancers of the lung and stomach. Cancer. 30: 75.

15. Yalow, R. S., and S. A. Berson. 1971. Fundamental 
principles of radioimmunoassay techniques in measurement of hormones. Excerpta Med. Int. Congr. Ser. 238: 16. 16. Orth, D. N., W. E. Nicholson, W. M. Mitchell, D. P.
Island, and G. W. Liddle. 1973. Biologic and im- munologic characterization and physical separation of ACTH and ACTH fragments in ectopic ACTH syndrome. J. Clin. Invest. 52: 1756.

17. Berson, S. A., and R. S. Yalow. 1968. Peptide hormones in plasma. Harvey Lect. Ser. 62. 107. 